\section{Science and psychosis}

John C. Marshall

The Cognitive Neuropsychology of Schizophrenia. By Christopher D. Frith. Lawrence Erlbaum: 1993. Pp. 169. £14.95, \$28.50.

"I FEEL a piercing stare from behind. I feel people want to harm me but I will not fight and my enemy will be disarmed." The writer is Vaslav Nijinsky, Le Dieu de la Danse, retreating into madness as the greater insanity of the 'Great' War lurched to an exhausted halt. In the epilogue to the diary that he wrote in St Moritz during 1918-19, Nijinsky noted that "the doctors do not understand my illness", a reflection that prompts the question whether, 75 years later, our present understanding of schizophrenia is materially better. Christopher Frith's monograph is a superb trampoline on which to bounce this question, for it provides both a succinct summary of what is known (or conjectured) and a highly original approach to the notion of explanation in psychiatric disorders.

As Frith points out, "schizophrenia is a surprisingly common illness with a life-time risk of approximately 1 in 100 people". The 'cost' of schizophrenia in terms of suffering is incalculable, but because the only values our society now accepts are based on market economics, Frith also reminds us that the cost "in terms of treatment, care, and skills lost to the community, is at least $2 \%$ of the gross national product". Yet despite the obvious magnitude of the problem, medical science cannot yet diagnose schizophrenia.

Lest this remark sound like mere wilful obfuscation, I should elaborate the grounds on which it is based. "Diagnosis [I quote the Oxford Companion to Medicine] is the process of identifying the disease or other circumstances responsible for the patient's complaints." No such disease has (yet) been identified as 'schizophrenia'. Rather, there are various classification schemes, based on check-lists of signs and symptoms that allow the physician to label patients as 'schizophrenic'. But the fact that psychiatrists can employ such checklists reliably and consistently is a far cry from discovering the underlying disorder (or disorders) responsible for the symptomatology.

These check-lists are furthermore grossly heterogeneous. The most commonly employed scheme (DSM-III-R) includes the characterization that schizophrenic psychosis must include two of the following symptoms: delusions, prominent hallucinations, incoherence, catatonic behaviour, flat or grossly in- appropriate affect. Whether these symptoms form a theoretically coherent group (or even a set of family resemblances) remains in doubt. The classification also contains the exclusionary criterion that there should be "no evidence of organic factors" involved. As Frith wryly notes, a truly bizarre paradox results: it is "widely believed that there is an organic basis to schizophrenia", but "a patient

\section{IMAGE UNAVAILABLE FOR COPYRIGHT REASONS}

\section{NijInsky as Petrushka.}

can only be diagnosed schizophrenic as long as the organic cause of the illness is unknown"!

In the first part of his monograph, Frith attempts to cut the Gordian knot by seeking explanations not of schizophrenia but rather of particular schizophrenic symptoms. Consider the main symptom of vocal hallucinations (hearing voices). Frith provides convincing experimental evidence against the notion that patients misperceive (and hence misinterpret) external auditory stimulation, and the beginnings of evidence for the notion that patients fail to recognize their own subvocal speech as their own. He then attempts to show how such failures of "self-monitoring" could in turn lead to a belief in (for example) "thought insertion" (where patients "experience thoughts coming into their mind from an outside source") or "delu- sions of control" (where "patients experience their actions as being controlled by an outside force").

In the concluding chapter, Frith then looks at both a tour de force and a volte-face in which schizophrenic disorders of willed action, of selfmonitoring and of monitoring the intentions of others are all brought together as a unitary impairment of the ability to form "metarepresentations". In autism, the child "does not try to infer the mental states of others"; in adult schizophrenia, the patients misrepresent their own and other people's propositional attitudes to the content of their thought. This section fits poorly with the rest of the book and betrays evidence of "overinclusive" thinking, as Frith himself slyly lets slip. The notion is so striking, however, that one hopes that Frith will develop the idea with the same close 일 attention to fact and logic demonstrated in the other chapters.

Throughout those chapters, Frith links particular schizophrenic signs and symptoms with malfunction of particular brain regions that are known (from studies of other pathologies) to be responsible for specific cognitive processes. These brain systems constitute a corticostriatal loop whose functioning is modulated by the neurotransmitter dopamine. Drugs that block dopamine receptors remain the most effective treatment for the florid positive symptoms of acute schizophrenia. But, as Frith notes, their exact mode of operation remains controversial and the linking hypotheses that mediate between biology and behaviour need to be spelled out in considerably more detail than is currently available. "Oversensitivity to dopamine" does not in itself constitute an explanation of vocal hallucinations and paranoid delusions.

There is also, sadly, evidence that some of the cognitive impairments seen in chronic 'burnt-out' schizophrenia are "a necessary consequence of the mechanism by which dopamine blockade reduces positive symptoms". These sideeffects include reduction of spontaneous activity and severe difficulties with concentration, although a similar deterioration was often seen in the days before the introduction of antipsychotic drugs. The ubiquitous Harry, Count Kessler, was shocked to encounter Nijinsky in the foyer of the Paris Opéra in December 1928: "His face, so often radiant as a god's, for thousands an unforgettable experience, was now gray, flabby, empty, only fleetingly lit by a blank smile, a brief gleam as of a flickering flame. Not a word crossed his lips."

John C. Marshall is in the Neuropsychology Unit, University Department of Clinical Neurology, Radcliffe Infirmary, Oxford OX2 $6 H E$, UK. 